\title{
THE INFLUENCE OF CYCLE LEARNING MODEL INTEGRATED BY THINK PAIR SHARE AND STUDENT TEAM ACHIEVEMENT DIVISION ON QUALITY OF PROCESSES AND COGNITIVE LEARNING OUTCOMES
}

\author{
Amar Atus Sholikah, Nanang Zubaidi \\ SMA Negeri I Parang, Magetan Jl. Raya Parang No 27, Magetan. \\ Email: tyabunder@gmail.com
}

\begin{abstract}
Hydrocarbons are one of the materials from Chemistry that studies abstract concepts and procedural knowledge. To study hydrocarbon material, students must master well the concepts related to previous concepts such as the concept of covalent bonding and equalizing reactions. The application of the Learning Cycle 5E learning model combined with cooperative type TPS and cooperative type STAD can be used as an alternative to developing a more meaningful learning atmosphere in understanding concepts and giving students the opportunity to work together to solve problems. The purpose of this study was to determine: the quality of the learning process using the LC 5E - TPS and LC 5E - STAD models on the topic of hydrocarbons, as well as differences in the cognitive learning outcomes of hydrocarbon students who were taught with these two learning models. This study uses a quasi-experimental design with "Postest Only Group Design". The sample of this study was students of class XI IPA1 and class XI IPA2 of SMAN I Parang in the 2019/2020 school year, each consisting of 21 people. Class XI IPAI as an experimental class taught with LC 5E - TPS model and class XI IPA2 as an experimental class taught with LC 5E-STAD model. Research data in the form of observations of the quality of the learning process, the results of observations of students 'cooperative abilities and students' post test scores. Research data were analyzed using $t$ test. The results showed that the quality of the learning process by using the LC 5E - TPS model and the LC 5E - STAD model were included in both categories. Students' cooperative skills in both learning models are included in both categories. Cognitive learning outcomes of students in learning with the LC 5E-TPS model are higher than in learning with the LC 5E-STAD model.
\end{abstract}

Keywords: hydrocarbons, LC 5E - TPS learning model, LC 5E - STAD learning model, process quality and learning outcomes.

\section{PENDAHULUAN}

Siklus belajar (Learning Cycle)
5Emerupakan model pembelajaran
yangberorientasi pada teori Piaget dan
teoripembelajaran kognitif serta aplikasi
modelpembelajaran konstruktivis. Model siklus
belajarsains merupakan suatu cara berpikir
danbertindak yang sesuai dengan bagaimana
siswabelajar. Dalam siklus belajar, siswa terlibat
langsung dalam kegiatan penyelidikan (hands on
activities) untuk mengembangkan pemahaman
terhadap suatu konsep sebelum diperkenalkan
dengan kata-kata atau informasi dari buku [1].
Dengan demikian siklus belajar juga
dapatmengembangkan keterampilan proses dan
keterampilan berpikir kritis siswa.

Selain model learning Cycle - 5E model pembelajaran kooperatif juga dapat digunakan sebagai alternatif agar siswa dapat membangun sendiri pengetahuannya dan memperoleh kesempatan untuk berinteraksi satu sama lain sehingga proses pembelajaran menjadi menarik, menyenangkan dan tidak membosankan. Slavin (2008) berpendapat bahwa belajar melalui kooperatif mempunyai perspektif motivasi artinya bahwa penghargaan yang diberikan kepada kelompok memungkinkan setiap anggota kelompok akan saling membantu [2]. 
Salah satu metode pembelajaran kooperatif yang dapat digunakan adalah metode Think Pair Share (TPS). Model pembelajaran kooperatif tipe TPS memiliki ciri khas pada tiga langkah pembelajarannya yang meliputi tahapthink(berpikir secara individual), pair (berpasangan), dan share (berbagi dengan pasangan lain atau seluruh kelas) [3]. Menurut Kagan(2009), model TPS mempunyai beberapa keunggulan.Keunggulan dari model TPS adalah mudah untuk diterapkan pada berbagai tingkat kemampuan berpikir dan dalam setiap kesempatan [4]. Siswa diberi waktu lebih banyak berpikir, menjawab, dan saling membantu satu sama lain. Model TPS cocok diterapkan untuk siswa yang kurang aktif agar lebih meningkatkan aktivitasnya dalam proses pembelajaran.

Selain model kooperatif TPS, model kooperatif tipe Student Team Achievement Divission (STAD) juga dapat digunakan untuk menciptakan suasana pembelajaran yang membuat siswa menjadi lebih aktif. Slavin (2008) menyatakan bahwa Model pembelajaran kooperatif tipe STAD adalah suatu model pembelajaran yang membagi atau menempatkan siswa ke dalam kelompok-kelompok, di mana setiap kelompok terdiri dari 4-5 orang secara heterogen berdasarkan tingkat kemampuan, jenis kelamin, dan latar belakang etnik [2].

Model pembelajaran lain yang dapat digunakan adalah perpaduan model learning Cycle $-5 E$ dengan pembelajaran kooperatif tipe STAD atau TPS. Adanya integrasi model kooperatif ke dalam learning Cycle $-5 E$ diharapkan agar siswa bisa menguasai konsepkonsep materi hidrokarbon dengan lebih baik dan meningkatkan aktivitas dan kerjasama antar siswa. Penggabungan model pembelajaranlearning Cycle $-5 E$ dan kooperatif tipe TPS dan STAD ini juga bermaksud memberikan variasi cara pembelajaran kepada siswa agar proses pembelajaran yang dilakukan tidak monoton dan membosankan. Adanya variasi cara pembelajaran tersebut pada akhirnya diharapkan dapat meningkatkan kualitas proses dan hasil belajar siswa [5]

Dalam model LC-5Eyang dipadu pembelajaran kooperatif tipe TPS atau STAD, pembelajaran terdiri dari 5 tahap yakni: engagement,eksploraton, explanation, elaboration, dan evaluation, dimana tahap kedua, tiga dan empat dikolaborasikan dengan pembelajaran kooperatif tipe TPS dan STAD. Fase engagement dimaksudkan untuk menarik perhatian siswa, memunculkan rasa ingin tahu, mengakses kesiapan siswa, dan menetapkan arah pembelajaran [6]. Fase yang kedua adalah fase eksplore. Dalam fase ini siswa dilibatkan dalam pengalaman bermakna, serta memperoleh landasan pengalaman melalaui eksplorasi, kerjasama, interaksi dengan siswa lain. Pada fase inilah dipadukan model pembelajaran kooperatif tipe TPS atau STAD, agar siswa bisa berinteraksi dengan baik dengan sesama siswa. Fase yang ketiga adalah explain, yakni siswa mengkomunikasikan ide-ide mereka menjelaskan tentang pemahaman konsep-konsep yang mereka pelajari kepada teman mereka dalam satu kelompok pembelajaran kooperatif tipe TPS atau STAD, dan juga kepada seluruh kelas [6].

Fase keempat adalah elaborate, dalam hal ini model kooperatif TPS dan STAD juga dapat dipadukan lagi agar siswa dapat bekerja sama menerapkan konsep baru ke dalam situasi baru.Fase yang terakhir adalah evaluate, sehingga guru dan siswa bisa mengevaluasi hasil belajar yang telah dilaksanakan [6].

Beberapa peneliti yang menggunakan model pembelajaran learning Cycle -5E, kooperatif tipe TPS dan STAD antara lain Ninis dkk (2005), Titisari (2010), Anah dkk (2013), Trent (2013). Penelitian-penelitian tersebut menunjukkan bahwa model-model pembelajaran tersebut efektif untuk meningkatkan hasil belajar siswa $[1,7,8,13]$.

Berdasarkan uraian tersebut maka dilakukan penelitian tentang pengaruh model pembelajaran Learning Cycle -5E dipadu Think Pair Share dan model pembelajaran Learning Cycle -5E dipadu Student Team Achievement Divission terhadap kualitas proses belajar, hasil belajar kognitif siswa pada topik hidrokarbon.

\section{METODE PENELITIAN}

Penelitian ini menggunakan rancangan penelitian kuasi eksperimen (quasi experiment) dengan "Postest Only Group Design" untuk menguji hasil belajar siswa yang dibelajarkan dengan dua model pembelajaran yang berbeda. Terdapat dua kelas eksperimen yang ditetapkan sebagai sampel penelitian. Kelas eksperimen pertama dibelajarkan dengan model Learning Cycle 5E dipadu Think Pair Share (kelas LC 5E $T P S)$ dan kelas eksperimen yang kedua dibelajarkan dengan model Learning Cycle5E dipadu Student Team Achievenement Divission 
(kelas LC 5E - STAD). Bagan rancangan penelitian dapat dilihat pada Tabel 3.1 berikut:

\section{Tabel 1 Bagan Rancangan Penelitian}

\begin{tabular}{lccc}
\hline \multicolumn{1}{c}{ Subyek } & Pretest & Perlakuan & Postest \\
\hline Kelas & - & $\mathrm{X}_{1}$ & $\mathrm{O}_{1}$ \\
Eksperimen 1 & & $\mathrm{X}_{2}$ & $\mathrm{O}_{2}$ \\
Kelas & - & & \\
Eksperimen 2 & - &
\end{tabular}

Keterangan :

$\mathrm{O}_{1}$ dan $\mathrm{O}_{2}=$ tes akhir setelah perlakuan

$\mathrm{X}_{1} \quad=\operatorname{model} L C 5 E-T P S$

$\mathrm{X}_{2} \quad=\operatorname{model} L C 5 E-S T A D$

Dalam penelitian ini, diajukan beberapa variabel yang terkait, yaitu sebagai berikut.

1. Variabel bebas: model pembelajaran Learning Cycle dipadu Think Pair Share dan model pembelajaran Learning Cycle dipadu Student Team Achievement Divission.

2. Variabel terikat: hasil belajar siswa yang dibelajarkan dengan model Learning Cycle dipadu Think Pair Share dan model Learning Cycle dipadu Student Team Achievement Divission.

3. Variabel kontrol: guru, materi yang diajarkan dan media pembelajaran yang digunakan.

Populasi dari penelitian adalah seluruh siswa kelas XI IPA SMA Negeri I Parang tahun ajaran 2019/2020 yang terdiri dari 3 kelas yakni XI IPA1 sampai dengan XI IPA3 yang sedang melaksanakan pembelajaran kimia. Pemilihan kelas XI IPA ini berdasarkan pada topik yang akan digunakan dalam pembelajaran yakni hidrokarbon. Guru kimia kelas XI IPA menyatakan bahwa tidak ada kelas unggulan untuk kelas XI IPA sehingga siswa XI IPA tersebut mempunyai kemampuan yang homogen. Hal ini juga didukung oleh nilai rata-rata raport pada semester sebelumnya yang homogen. Berdasarkan teknik sampling simple random sampling, ditetapkan dua kelas sebagai sampel yakni kelas XI IPA1 dan XI IPA2 yang masingmasing terdiri dari 21 orang (Tabel 3.2).

\section{Tabel 2 Data Siswa Sebagai Sampel Penelitian}

\begin{tabular}{cccc}
\hline No & Kelas & $\begin{array}{c}\text { Jumlah } \\
\text { Siswa }\end{array}$ & Kelas \\
\hline 1 & XI IPA1 & 21 & Eksperimen 1 \\
2 & XI IPA2 & 21 & Eksperimen 2 \\
\hline
\end{tabular}

Instrumen perlakuan yang digunakan untuk melaksanakan proses pembelajaran yang terdiri dari Rencana Pelaksanaan Pembelajaran (RPP), hands-out dan Lembar Kerja Siswa (LKS). Instrumen perlakuan pembelajaran untuk kedua kelas eksperimen dilakukan dalam waktu dan porsi materi pelajaran yang sama.

RPP merupakan penjabaran untuk tiap pertemuan dalam kegiatan pembelajaran. RPP yang digunakan terdiri dari dua macam yakni RPP untuk kelas eksperimen 1 dengan model pembelajaran Learning Cycle5E dipadu Think Pair Share (LC 5E - TPS) dan dan RPP untuk kelas eksperimen 2 dengan model pembelajaran Learning Cycle5Edipadu Student Team Achievement Divission Learning Cycle (LC 5E $S T A D)$. Kedua RPP tersebut dikembangkan sesuai dengan langkah-langkah yang ada dalam model yang digunakan. Garis besar perlakuan pada kelas dengan model pembelajaran Learning Cycle5Edipadu Think Pair Share (LC 5E - TPS) dan model pembelajaran Learning Cycle dipadu Student Team Achievement Divission Learning Cycle 5E(LC 5E - STAD) disajikan dalam Tabel 3.3 dan Tabel 3.4

Tabel 33 Garis Besar Perlakuan pada Kelas dengan Model Pembelajaran Learning Cycle-5E Dipadu Think Pair Share

\begin{tabular}{|c|c|}
\hline No & Kegiatan Pembelajaran \\
\hline 1 & $\begin{array}{l}\text { Awal (engagement) } \\
\text { 1. Guru membuka pelajaran, mengakses } \\
\text { kesiapan siswa } \\
\text { 2. Guru menyampaikan tujuan pembelajaran, } \\
\text { menetapkan arah pembelajaran } \\
\text { 3. Guru melakukan tanya jawab untuk } \\
\text { mengetahui pengetahuan awal siswa } \\
\text { menarik perhatian siswa, memunculkan rasa } \\
\text { ingin tahu }\end{array}$ \\
\hline 2 & $\begin{array}{l}\text { Inti } \\
\text { 1. Guru menyampaikan materi pelajaran } \\
\text { (explore) } \\
\text { 2. Guru memberi kesempatan kepada siswa } \\
\text { untuk bertanya } \\
\text { 3. Guru membagi siswa ke dalam kelompok } \\
\text { TPS yang beranggotakan } 2 \text { orang sebagai } \\
\text { pasangan belajar (elaborate). } \\
\text { 4. Guru memberi kesempatan kepada siswa } \\
\text { untuk mengerjakan LKS secara individu } \\
\text { (fase think) kemudian mendiskusikannya } \\
\text { bersama pasangan belajar (fase pair, } \\
\text { elaborate, explore dan explain). } \\
\text { 5. Guru mempersilakan siswa untuk } \\
\text { mempresentasikan hasil pekerjaannya } \\
\text { dalam diskusi kelas (fase share dan } \\
\text { explain). }\end{array}$ \\
\hline
\end{tabular}


6. Guru memberikan kondisi lain dan memberi kesempatan kepada siswa untuk mengerjakan LKS secara individu (fase think) kemudian mendiskusikannya bersama pasangan belajar (fase pair, elaborate, explore dan explain), sementara assesmen dilakukan.

7. Guru mempersilakan siswa untuk mempresentasikan dan membahas soal bentukannya dalam kelas (explain).

8. Pelaksanaan kuis dan ulangan harian (evaluation)

$3 \quad$ Penutup

1. Guru memberikan penghargaan terhadap kerja siswa dalam kelompok.

2. Guru mengarahkan siswa untuk menarik kesimpulan

3. Guru membuat rangkuman berdasarkan kesimpulan siswa

4. Guru menutup pembelajaran

Tabel 4 Garis Besar Perlakuan pada Kelas dengan Model Pembelajaran Learning Cycle - 5E Dipadu Student Team Achievement Divission

\begin{tabular}{ll}
\hline No & \multicolumn{3}{c}{ Kegiatan Pembelajaran } \\
\hline 1 & Awal (engagement) \\
& 1. Guru membuka pelajaran, mengakses \\
& kesiapan siswa \\
2. Guru menyampaikan tujuan pembelajaran, & menetapkan arah pembelajaran \\
& 3. Guru melakukan tanya jawab untuk \\
& mengetahui pengetahuan awal siswa \\
& menarik perhatian siswa, memunculkan rasa \\
& ingin tahu
\end{tabular}

$2 \quad$ Inti

1.Guru menyampaikan materi pelajaran (explore)

2. Guru memberi kesempatan kepada siswa untuk bertanya

3. Guru membagi siswa ke dalam kelompokkelompok STAD yang beranggotakan 4-5 orang (elaborate)

4. Guru memberi kesempatan kepada siswa untuk mengerjalan soal dari LKS yang diberikan serta mendiskusikannya di dalam kelompok(fase elaborate, explore dan explain)

5. Gurumempersilakan siswa untuk mempresentasikan pekerjaan mereka dalam diskusi kelas (explain)

6. Guru memberikan kondisi lain dan memberikan kesempatan kepada siswa untuk berpikir, mengerjakan dan mendiskusikannya dalam kelompok(fase elaborate, explore dan explain), sementara assesmen dilakukan.

7. Guru mempersilakan siswa untuk mempresentasikan dan membahas soal bentukannya dalam kelas (explain).

8. Pelaksanaan kuis dan ulangan harian (evaluation)

$3 \quad$ Penutup

1. Guru meberikan penghargaan terhadap kerja siswa dalam kelompok.

2. Guru mengarahkan siswa untuk menarik kesimpulan

3. Guru membuat rangkuman berdasarkan kesimpulan siswa

4. Guru menutup pembelajaran

Hands-out berisi uraian bahan ajar yang dibuat oleh guru yang digunakan sebagai bahan dasar bagi guru dan siswa dalam proses pembelajaran di kelas. Hands-out dibuat dengan maksud untuk memberikan bantuan informasi atau materi pembelajaran sebagai pegangan bagi siswa. Lembar Kerja Siswa (LKS) digunakan untuk membantu siswa dalam memahami topik hidrokarbon. LKS berisi soal-soal yang telah dibuat oleh guru sesuai kondisi yang diinginkan untuk kemudian diselesaikan oleh siswa bersama teman dalam kelompoknya.

Instrumen pengukuran yang digunakan untuk mengukur hasil perlakuan pada penelitian ini terdiri dari dua jenis, yaitu: a) instrumen penilaian hasil belajar kognitif, dan b) instrumen yang berupa lembar observasi untuk menilai kualitas proses pembelajaran. Tes hasil belajar (post-test) dilakukan setelah siswa pada kedua kelas eksperimen melaksanakan proses pembelajaran hidrokarbon. Tes yang digunakan adalah multiple choice test yang berjumlah 30 butir soal. Multiple choice tests merupakan tes pilihan ganda dengan beberapa pilihan jawaban yang harus dipilih oleh siswa. Waktu yang digunakan untuk mengerjakan tes ini adalah 90 menit.

Instrumen penilaian kualitas proses belajar digunakan untuk mengukur dan mengetahui kualitas proses belajar siswa yang sedang berlangsung. Instrumen ini terdiri dari lembar observasi keterlaksanaan pembelajaran dan lembar observasi aktivitas kooperatif siswa terhadap kedua jenis model pembelajaran yang diterapkan. Instrumen tersebut digunakan untuk memonitor dan mendeskripsikan jalannnya proses pembelajaran, yaitu apakah langkahlangkah pembelajaran yang digunakan oleh guru telah sesuai dengan langkah-langkah pada model Learning Cycle - 5E dipadu Think Pair Share maupun model Learning Cycle- 5E dipadu Student Team Achievement Divission pada topik 
hidrokarbon, dan bagaimana kegiatan siswa selama proses pembelajaran berlangsung.

Analisis data yang dilakukan bertujuan untuk memberikan makna terhadap data yang telah dikumpulkan dari sampel penelitian dengan menggunakan nilai tes akhir dan hasil observasi untuk mendapatkan suatu kesimpulan. Data yang didapatkan dianalisa secara deskriptif maupun dengan menggunakan uji t. Analisa deskriptif digunakan untuk menggambarkan proses pembelajaran. Analisis ini diperlakukan untuk data-data hasil observasi. Analisis uji t digunakan untuk menguji hasil belajar kognitif siswa.

\section{Uji Normalitas}

Uji ini digunakan untuk mengetahui apakah data yang digunakan dalam penelitian terdistribusi normal atau tidak. Normalitas data merupakan syarat pokok yang harus dipenuhi dalam analisis parametric [9]. Jika data terdistribusi normal, berarti data tersebut dapat mewakili populasi. Uji normalitas dalam penelitian ini menggunakan program SPSS 20 for windows yaitu Normality Test melalui prosedur One Sample Kolmogorov-Smirnov. Langkah yang digunakan yaitu Analyze $\rightarrow$ Nonparametric Tests $\rightarrow 1$ Sample K-S. Jika skor signifikansi (Asymp. Sig 2-tailed) lebih dari 0,05 maka data berdistribusi normal dan sebaliknya, jika skor signifikansi (Asymp. Sig 2-tailed) kurang dari 0,05 maka data tidak berdistribusi normal [10].

\section{Uji homogenitas}

Uji homogenitas digunakan untuk mengetahui apakah kedua sampel yang diambil mempunyai varian data yang sama atau tidak. Uji homogenitas dalam penelitian ini menggunakan program SPSS 20 for windows yakni Uji Levene's. Langkah yang digunakan yaitu Analyze $\rightarrow$ Compare Means $\rightarrow$ One Way Anova $\rightarrow$ Deskriptive \& Homogenity. Pedoman dalam pengambilan keputusan adalah jika nilai signifikansinya lebih dari 0,05 berarti data varian tersebut homogen. Sebaliknya jika nilai signifikansinya kurang dari 0,05 data berasal dari varian yang berbeda [10].

\section{Uji Hipotesis}

Data berupa skor tes akhir selanjutnya dianalisis dengan melalui teknik analisis independent sample $t$ test atau uji t menggunakan program SPSS 20 for windows. Analisis ini digunakan untuk menguji hipotesis yang diajukan. Hipotesis yang diuji adalah $\mathrm{H}_{1}$ : "terdapat perbedaan hasil belajar antara siswa yang dibelajarkan dengan model Learning Cycle $5 E$ dipadu dengan kooperatif TPS dan siswa yang dibelajarkan dengan model Learning Cycle- $5 E$ dipadu dengankooperatif STAD. Jika skor signifikansi kurang dari 0,05 berarti terdapat perbedaan hasil belajar siswa pada kedua kelas eksperimen dan sebaliknya, jika skor signifikansi lebih dari 0,05 berarti tidak ada perbedaan hasil belajar siswa pada kedua kelas eksperimen tersebut [10]. Adapun tahapan uji t dua sampel independen yaitu Analyze $\rightarrow$ Compare means $\rightarrow$ Independent Sample T Test.

\section{HASIL PENELITIAN DAN PEMBAHASAN}

Dalam bab ini dipaparkan hasil penelitian yang meliputi (a) deskripsi data kemampuan awal siswa; (b) data kualitas proses pembelajaran; dan (c) data hasil belajar siswa model pembelajaran Learning Cycle dipadu Think Pair Share dan model pembelajaran Learning Cycle dipadu Student Team Achievement Divission.

\section{Data Kemampuan Awal siswa}

Data kemampuan awal siswa diperoleh dari nilai ulangan harian materi prasyarat yakni pada bab ikatan kimia. Data tersebut digunakan untuk mengetahui bahwa kedua kelas mempunyai kemampuan awal yang setara dalam menerima materi yang akan dibelajarkan pada penelitian. Pada Tabel 5 dipaparkan data kemampuan awal siswa pada kedua kelas eksperimen.

Tabel 5 Data Kemampuan Awal Siswa

\begin{tabular}{lccccc}
\hline Kelas & N & Mean & $\begin{array}{c}\text { Std. } \\
\text { Deviasi }\end{array}$ & $\begin{array}{c}\text { Mini- } \\
\text { mum }\end{array}$ & $\begin{array}{c}\text { Maksi- } \\
\text { mum }\end{array}$ \\
\hline $\begin{array}{l}\text { LC 5E- } \\
\begin{array}{l}\text { TPS } \\
\text { LC 5E- }\end{array}\end{array}$ & 21 & 65,86 & 12,95 & 48 & 89 \\
$\begin{array}{l}\text { STAD } \\
\text { 21 }\end{array}$ & 63,90 & 13,02 & 40 & 85 \\
\hline
\end{tabular}

Pada Tabel 5 diketahui bahwa skor rata-rata kemampuan awal siswa pada kelas yang dibelajarkan dengan model Learning Cycle dipadu Think Pair Share (kelas LC 5E-TPS)dan model Learning Cycle dipadu Student Team Achievement Divission(kelas LC 5E-STAD) masing-masing sebesar 65,86 dan 63,90.

Hasil uji normalitas, uji homogenitas dan uji $\mathrm{t}$ yang dilakukan menggunakan program SPSS 20 for Windows pada data kemampuan awal siswa kelas LC 5E - TPS dan kelas LC 5E - STAD dapat dilihat pada Tabel 6. 
Tabel 6 Nilai Signifikansi Uji Normalitas, Homogenitas dan Uji t Kemampuan Awal Siswa

\begin{tabular}{lccc}
\hline \multicolumn{1}{c}{ Kelas } & $\begin{array}{c}\text { Uji } \\
\text { Normalitas }\end{array}$ & $\begin{array}{c}\text { Uji } \\
\text { Homogenitas }\end{array}$ & Uji t \\
\hline LC 5E-TPS & 0,728 & 0,699 & 0,629 \\
LC 5E-STAD & 0,660 & & \\
\hline
\end{tabular}

Berdasarkan uji normalitas kemampuan awal siswa melalui One Sample Kolmogorov Smirnov Test dapat diketahui bahwa siginfikansinya sebesar 0,728 untuk kelas LC 5E-TPS dan 0,660 untuk kelas LC 5E-STAD. Nilai tersebut lebih besar dari 0,05 . Oleh karena itu, seluruh data pada kedua kelas eksperimen dinyatakan terdistribusi normal.

Hasil uji homogenitas data kemampuan awal siswa menggunakan Test of Homogenity of Variances, dapat diketahui dari nilai Levene's Test. Dari uji tersebut diperoleh nilai signifikansi sebesar 0,699 . Nilai tersebut lebih dari 0,05 , maka dapat disimpulkan bahwa data terdistribusi secara homogen.

Dari perhitungan uji t melaui SPSS 20 for Windows diperoleh signifikansi sebesar 0,629. Nilai tersebut lebih dari 0,05. Oleh karena itu dapat disimpulkan bahwa tidak ada perbedaan rata-rata kemampuan awal siswa pada kedua kelas eksperimen.

\section{Data Kualitas Proses Pembelajaran}

Data kualitas proses pembelajaran meliputi: data keterlaksanaan proses pembelajaran dan data aktivitas kooperatif siswa

Dari penelitian yang telah dilakukan pada kedua kelas eksperimen, diperoleh data hasil pengamatan terhadap keterlaksanaan dalam proses pembelajaran. Tabel 4.3 memperlihatkan skor ratarata keterlaksanaan pembelajaran selama penerapan tiga RPP pada kedua kelas eksperimen. Persentase keterlaksanaan pembelajaran dihitung dari rata-rata perolehan skor dibagi dengan skor harapan (empat) dikali $100 \%$.

Tabel 7 Deskripsi Keterlaksanaan Proses Pembelajaran pada Kelas LC 5E - TPS dan Kelas LC 5E - STAD

\begin{tabular}{llcc}
\hline \multirow{2}{*}{ RPP ke } & \multicolumn{2}{c}{ Rata-rata Perolehan Skor } \\
\cline { 3 - 4 } & Tahap & Kelas & Kelas \\
& Pembelajaran & LC 5E - & LC 5E - \\
& & TPS & STAD \\
\hline I & Awal & 3,7 & 3,3 \\
& Inti & 3,3 & 3,1 \\
& Penutup & & 3,3
\end{tabular}

\begin{tabular}{|c|c|c|c|}
\hline & Rata-rata & $3,2 \quad(80 \%)$ & $3,2(80 \%)$ \\
\hline \multirow[t]{4}{*}{ II } & Awal & 3,7 & 3,7 \\
\hline & Inti & 3,3 & 3,4 \\
\hline & Penutup & 3,3 & 3,7 \\
\hline & Rata-rata & $3,4(85 \%)$ & $3,5(88 \%)$ \\
\hline \multirow[t]{4}{*}{ III } & Awal & 3,7 & 3,7 \\
\hline & Inti & 3,4 & 3,4 \\
\hline & Penutup & 3,7 & 3,7 \\
\hline & Rata-rata & $3,5(88 \%)$ & $3,5(88 \%)$ \\
\hline & ta dari 4 RPP & $84,33 \%$ & $85,33 \%$ \\
\hline
\end{tabular}

Kriteria: $81-100 \%$ = sangat baik

$$
\begin{aligned}
& 61-80 \%=\text { baik } \\
& 41-60 \%=\text { cukup } \\
& 21-40 \%=\text { kurang } \\
& 0-20 \%=\text { sangat kurang }
\end{aligned}
$$

Pembelajaran materi hidrokarbon yang telah dilaksanakan di SMAN I Parang kelas XI IPA1 dan XI IPA2 terbagi dalam sembilan kali pertemuan. Kelas XI IPA1 dibelajarkan dengan model Learning Cycle dipadu Think Pair Share. Kelas XI IPA2 dibelajarkan dengan model Learning Cycle dipadu Student Team Achievement Divission. Masing-masing kelas menggunakan tiga RPP yang telah dikembangkan sesuai dengan model pembelajaran yang digunakan.

Pada pelaksanaan RPP pertama, siswa mempelajari definisi senyawa hidrokarbon, kekhasan atom karbon, posisi atom karbon dan penggolongan senyawa karbon. Pada pelaksanaan RPP kedua, siswa mempelajari tata nama dan jenis-jenis isomer alkana, alkena dan alkuna. Pada pelaksanaan RPP ketiga, siswa mempelajari reaksi-reaksi hidrokarbon dan kegunaan hidrokarbon.

Berdasarkan Tabel 7, diketahui bahwa ratarata keterlaksanaan 4 RPP untuk kelas LC 5E TPS adalah $84,33 \%$ dan untuk kelas LC 5E STAD adalah 85,33\%. Oleh karena itu keterlaksanaan proses pembelajaran kedua model tersebut tergolong baik [11].

Data aktivitas siswa dalam kegiatan pembelajarandiperoleh dari hasil observasi. Fokus observasi adalah keterlaksanaan indikator pembelajaran yang meliputi indikator pertanggungjawaban individu, saling ketergantungan positif, interaksi langsung antar siswa, keterampilan sosial dan keefektifan proses kelompok. Data hasil observasi aktivitas kooperatif siswa dalam pembelajaran Learning Cycleyang dipadu TPS dan STAD dapat dilihat pada Tabel 8 
Tabel 8 Nilai Rata-rata Aktivitas Koperatif Siswa pada Tiap RPP

\begin{tabular}{lcccc}
\hline \multirow{2}{*}{ RPP } & \multicolumn{2}{c}{ Kelas LC 5E - TPS } & \multicolumn{2}{c}{ Kelas LC 5E - STAD } \\
\cline { 2 - 5 } & $\begin{array}{c}\text { Nilai } \\
\text { rata-rata }\end{array}$ & Kriteria & $\begin{array}{c}\text { Nilai } \\
\text { rata-rata }\end{array}$ & Kriteria \\
\hline 1 & 76,50 & Baik & 75,60 & Baik \\
2 & 80,20 & Baik & 81,50 & Baik \\
3 & 82,90 & Baik & 82,60 & Baik \\
\hline $\begin{array}{c}\text { rata- } \\
\text { rata }\end{array}$ & 79,86 & Baik & 79,26 & Baik \\
\hline
\end{tabular}

Kriteria: $86-100=$ sangat baik

71-85 = baik $\quad 56-70=$ cukup

Dari data pada Tabel 4.4 dapat dibuat diagram seperti yang tercantum pada Gambar 4.3.

\section{Nilai rata-rata}

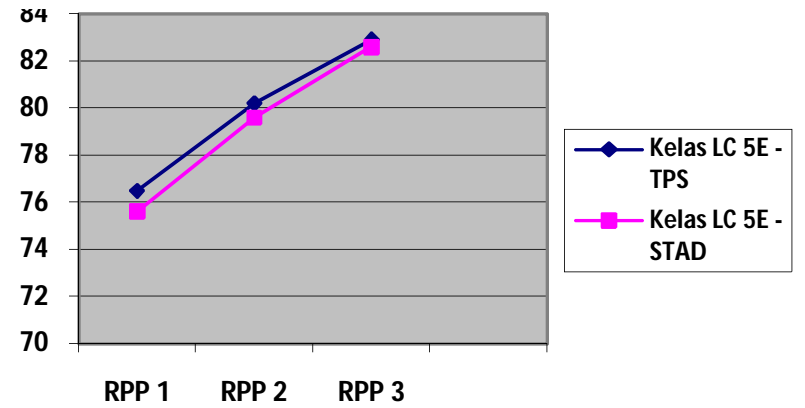

Gambar 1 Diagram Aktivitas Kooperatif Siswa Kelas LC 5E - TPS dan Kelas LC 5E - STAD pada Tiap RPP

\section{Data Hasil Belajar Siswa}

Berdasarkan penelitian yang dilakukan di SMAN 1 Parang, didapatkan data hasil belajar siswa pada materi hidrokarbon. Hasil belajar tersebut meliputi data hasil penilaian kognitif pada kelas eksperimen yang dibelajarkan dengan model pembelajaran Learning Cycleyang dipadu dengan kooperatif TPS maupun kelas eksperimen yang dibelajarkan dengan model pembelajaran Learning Cycleyang dipadu dengan kooperatif STAD. Hasil belajar kognitif diperoleh melalui nilai post test materi hidrokarbon. Pada Tabel 4.5 dipaparkan rata-rata hasil belajar materi hidrokarbon pada kedua kelas eksperimen.

Tabel 9 Nilai Rata-rata Post TestSiswa Materi Hidrokarbon

Kelas LC 5E - TPS

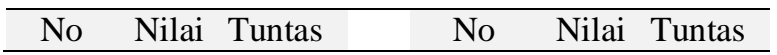

\begin{tabular}{llcccc}
\hline 1 & 63,3 & tidak & 13 & 96,7 & ya \\
\hline 2 & 90,0 & ya & 14 & 70,0 & ya \\
\hline 3 & 80,0 & ya & 15 & 90,0 & ya \\
\hline 4 & 60,0 & tidak & 16 & 76,7 & ya \\
\hline 5 & 83,3 & ya & 17 & 80,0 & ya \\
\hline 6 & 93,3 & ya & 18 & 96,7 & ya \\
\hline 7 & 76,7 & ya & 19 & 83,3 & ya \\
\hline 8 & 73,3 & ya & 20 & 83,3 & ya \\
\hline 9 & 60,0 & tidak & 21 & 83,3 & ya \\
\hline 10 & 63,3 & tidak & Jml & 1663 & 17 \\
\hline 11 & 70,0 & ya & Mean & 79,2 & $80,95 \%$ \\
\hline 12 & 90,0 & ya & & \\
\hline
\end{tabular}

\begin{tabular}{cccccc}
\hline \multicolumn{3}{c}{ Kelas LC 5E - STAD } & & & \\
\hline No & Nilai & Tuntas & No & Nilai & Tuntas \\
\hline 1 & 73,3 & ya & 13 & 66,7 & tidak \\
\hline 2 & 80,0 & ya & 14 & 90,0 & ya \\
\hline 3 & 60,0 & tidak & 15 & 60,0 & tidak \\
\hline 4 & 63,3 & tidak & 16 & 86,7 & ya \\
\hline 5 & 60,0 & tidak & 17 & 63,3 & tidak \\
\hline 6 & 83,3 & ya & 18 & 73,3 & ya \\
\hline 7 & 73,3 & ya & 19 & 70,0 & tidak \\
\hline 8 & 70,0 & ya & 20 & 60,0 & tidak \\
\hline 9 & 60,0 & tidak & 21 & 80,0 & ya \\
\hline 10 & 90,0 & ya & Jml & 1513 & 12 \\
\hline 11 & 73,3 & ya & Mean & 72.1 & $57,14 \%$ \\
\hline 12 & 73,3 & ya & & & \\
\hline \multicolumn{5}{c}{}
\end{tabular}

Tabel 10 Statistik Nilai Rata-rata Post Test Siswa Materi Hidrokarbon

\begin{tabular}{cccccc}
\hline Kelas & N & $\begin{array}{c}\text { Rata- } \\
\text { rata }\end{array}$ & $\begin{array}{c}\text { Std. Devi- } \\
\text { asi }\end{array}$ & $\begin{array}{c}\text { Mini } \\
\text { mum }\end{array}$ & $\begin{array}{c}\text { Maksi } \\
\text { mum }\end{array}$ \\
\hline LC 5E - TPS & 21 & 79.20 & 11.560 & 60 & 96.7 \\
LC 5E - STAD & 21 & 72.05 & 10.243 & 60 & 90.0 \\
\hline
\end{tabular}

Sebelum melakukan pengujian hipotesis, terlebih dahulu dilakukan uji prasyarat analisis yang meliputi uji normalitas dan uji homogenitas. Uji normalitas dilakukan data nilai post test siswa pada kedua kelas eksperimen.

Pada Tabel 11 dipaparkan hasil uji normalitas data yang diperoleh dengan menggunakan SPSS 20for Windows melalui One Sample KolmogorovSmirnov Test.

Tabel 11 Hasil Uji Normalitas Data Nilai Post Test dengan One SampleKolmogorov-Smirnov Test

\begin{tabular}{ccr}
\hline Kelas & Sig. (2-tailed) \\
\hline LC 5E - TPS & \multicolumn{3}{c}{.946} & \\
LC 5E - STAD & \multicolumn{6}{c}{.611} & \\
\hline Berdasarkan Tabel & 11 & dapat diketahui \\
bahwanilai signifikansi data & kedua kelompok \\
tersebut yakni 0,946 dan & $0,611$. Kedua nilai
\end{tabular}


signifikansi tersebut lebih dari 0,05, maka data dinyatakan terdistribusi normal.

Hasil uji homogenitas berdasarkan pada nilai Levene's Test dicantumkan pada Tabel 12.

Tabel 12 Hasil Uji Homogenitas Data Nilai Post Test

\begin{tabular}{cccc}
\hline Levene Statistic & df1 & df2 & Sig. \\
\hline .395 & 1 & 40 & .533 \\
\hline
\end{tabular}

Berdasarkan Tabel 4.8 dapat dilihat bahwa nilai signifikansi hasil uji homogenitas adalah 0,533. Nilai tersebut lebih dari 0,05 . Jadi, dapat disimpulkan bahwa secara keseluruhan data terdistribusi homogen.

Berdasarkan hasil uji normalitas dan homogenitas yang telah dilakukan, dapat disimpulkan bahwa data dalam penelitian ini telah terdistribusi normal dan homogen. Oleh karena itu, data dalam penelitian ini memenuhi persyaratan untuk dilakukan uji t. Deskripsi data hasil belajar siswa dapat dilihat pada hasil analisis $t$-test dengan menggunakan SPSS 20 for windows melalui Independent Sample Test. Hasil analisis uji $\mathrm{t}$ tersebut dapat dicermati pada Tabel 13.

Tabel 13 Hasil Uji t Data Nilai Post Test

\begin{tabular}{ccccc}
\hline Nilai & F & df2 & T & Sig. (2-tailed) \\
\cline { 2 - 5 } post test & 0.395 & 40 & 2.117 & .041 \\
\hline
\end{tabular}

Berdasarkan perhitungan SPSS 20 didapatkan nilai sig. (2-tailed) pada Tabel 13 sebesar 0,041 dan $\mathrm{t}_{\text {hit }}=2,117$. Nilai siginfikansi tersebut kurang dari 0,05 . Nilai $t_{\text {tab }}$ dengan derajad kebebasan 40 dan taraf kesalahan 0,05 adalah 2,018. Nilai $t_{\text {hit }}$ lebih dari nilai $t_{\text {tab. }}$. Hasil uji $t$ ini yang menunjukkan bahwa ada perbedaan hasil belajar siswa pada kedua model pembelajaran yang digunakan. Hasil belajar siswa di kelas LC 5E - TPS adalah lebih tinggi dari hasil belajar siswa di kelas LC 5E STAD.

Penilaian kualitas proses pembelajaran dilakukan untuk mendapatkan gambaran mengenai informasi tentang perilaku dan kemajuan belajar siswa terhadap proses pembelajaran. Penilaian kualitas proses pembelajaran yang berlangsung dapat diketahui dengan menggunakan lembar observasi. Selama pembelajaran yang dilaksanakan, peneliti meminta bantuan dua observer untuk mengamati jalannya pembelajaran. Pengamatan terhadap kualitas proses pada pembelajaran dengan model Learning Cycle dipadu Think Pair Share dan model Learning Cycle dipadu Student Team Achievement Divission meliputi aktivitas guru dan siswa selama proses pembelajaran. Hasil pengamatan observer tersebut dapat dilihat Tabel di atas..

Berdasarkan hasil observasi bahwa keterlaksanaan proses pembelajaran dengan model Learning Cycle dipadu Think Pair Share dan model Learning Cycle dipadu Student Team Achievement Divission ini secara keseluruhan maing-masing berlangsung dengan baik dengan rata-rata keterlaksanaaan sebesar $84,33 \%$ dan $85,33 \%$. Nilai rata-rata keterampilan kooperatif siswa selama kegiatan pembelajaran berlangsung adalah 79,86 untuk kelas LC 5E - TPS dan 79,26 untuk kelas LC 5E - STAD dengan kategori baik. Secara umum bahwa untuk setiap tahap model pembelajaran LC 5E - TPS dan LC 5E - STAD keduanya mempuanyai kualitas proses yang baik dan nilainya hampir sama.

Tahap-tahap pembelajaran menggunakan kedua model pembelajaran ini adalalah (1) kegiatan pendahuluan yang berisi penjelasan tujuan pembelajaran dan apresepsi, (2) kegiatan inti pembelajaran dan (3) penutup yang berisi pembuatan kesimpulan dan rangkuman pembelajaran oleh siswa yang dipandu oleh guru, serta pemberian tugas lanjutan untuk siswa untuk memperdalam pemahaman materi. Pada tahap pendahuluan, siswa dikondisikan siap untuk belajar. Siswa diberi penjelasan mengenai tujuan pembelajaran. Siswa diberikan apersepsi tentang kejadian yang dialami siswa dalam kehidupan sehari-hari yang dikaitkan dengan materi pembelajaran (Engagement). Kegiatan inti berisi tahap-tahap penting dalam pembelajaran dengan menggunakan model Learning Cycle dipadu Think Pair Share dan model Learning Cycle dipadu Student Avhievement Divission. Tahap-tahap ini antara lain penjelasan materi oleh guru, pemberian contoh-contoh soal beserta jawabannya, proses berfikir secara individu oleh siswa, pembuatan pasangan belajar dan kelompok belajar, pembahasan soal oleh siswa bersama pasangan atau kelompok belajar dan penyajian hasil kerja kelompok atau pasangan belajar di kelas. Tahap ini berlangsung dua kali dengan kondisi yang berlainan.

Tahap-tahap model pembelajaran Learning Cycle yang dipadu dengan kooperatif TPS ini mempunyai persamaan dengan tahap-tahap model pembelajaran Learning Cycle yang dipadu dengan kooperatif STAD. Persamaannya terletak pada kegiatan pendahuluan, penjelasan materi dan pemberian contoh soal pada kegiatan inti, dan penutup. LKS danhands-out yang digunakan pada kedua kelas eksperimen juga sama. Perbedaannya terletak pada kegiatan inti pembelajaran yaitu, 
setelah siswa membuat berpikir memecahkan masalah secara individu sesuai dengan kondisi yang diberikan oleh guru, siswa bertukar soal dan bekerja sama membahas soal-soal tersebut dalam kelompok yang terdiri dari dua orang pada kelas LC 5E - TPS dan terdiri dari lima orang dalam kelas LC 5E STAD.Tahap ini menekankan adanya aktivitas dan interaksi diantara siswa untuk saling memotivasi dan saling membantu dalam menguasai materi pelajaran [2].Pada fase inilah penilaian aktivitas kooperatif dalam kelompok atau pasangan belajar dilaksanakan. Setelah itu guru meminta beberapa perwakilan pasangan belajar dan kelompok belajar untuk menyelesaikan soal-soal di LKS dan membahasnya dalam dikusi kelas.

Secara keseluruhan RPP pertama untuk model LC 5E - TPS dapat terlaksana dan mendapatkan skor rata-rata 3,2 (80\%) dengan kategori baik. Secara keseluruhan RPP pertama untuk modelLC 5E - STADdapat terlaksana dan mendapatkan skor rata-rata 3,2 (80\%) dengan kategori baik.Sebagian besar tahap pembelajaran yang direncanakan terlaksana dengan baik. Ketidaksesuaian RPP terdapat pada waktu yang direncanakan karena siswa belum terbiasa belajar dengan model Learning Cycle dipadu Think Pair Share dan model Learning Cycle dipadu Student Team Achievement Divission, sehingga masih banyak pertanyaan siswa terkait dengan tahap-tahap pembelajaran yang harus dilakukan. Keterampilan kooperatif siswa secara umum termasuk dalam kategori baik yakn idengan nilai rata-rata 76,50 untuk kelas LC 5E - TPS dan 75,60 untuk kelas LC 5E - STAD

Secara keseluruhan RPP keduauntuk model LC 5E - TPS dapat terlaksana danmendapatkan skor rata-rata $3,4(85 \%)$ dengan kategori baik. Secara keseluruhan RPP pertama untuk model LC 5E - STAD dapat terlaksana danmendapatkan skor rata-rata 3,5 (88\%) dengan kategori baik.Sebagian besar tahap pembelajaran yang direncanakan terlaksana dengan baik. Pada pelaksanaan RPP yang kedua, siswa pada kedua kelas eksperimen sudah mulai terbiasa dengan model pembelajaran yang diterapkan yang dapat dilihat dari siswa sudah tidak banyak bertanya mengenai proses membuat pertanyaan berdasarkan kondisi yang diberikan di LKS. Keterampilan kooperatif siswa jugameningkat jika dibandingkan dengan pertemuan sebelumnya, dengan nilai rata-rata 80,20 untuk kelas LC 5E TPS dan 81,50 untuk kelas LC 5E - STAD. Hal ini karena siswa mulai terbiasa dengan pembelajaran kooperatif yang diterapkan.

Secara keseluruhan RPP ketigauntuk model LC 5E - TPS dapat terlaksana dan mendapatkan skor rata-rata 3,5 (88\%) dengan kategori baik.
Secara keseluruhan RPP pertama untuk model LC 5E - STAD dapat terlaksana dan mendapatkan skor rata-rata 3,5 (88\%) dengan kategori baik. Sebagian besar tahap pembelajaran yang direncanakan terlaksana dengan baik. Pada pelaksanaan RPP yang ketiga, siswa pada kedua kelas eksperimen sudah terbiasa dengan model pembelajaran yang diterapkan. Nilai rata-rata keterampilan kooperatif juga cenderung mengalami peningkatan jika dibandingkan dengan RPP sebelumya.

Berdasarkan hasil uji hipotesis pada Tabel di atas, diketahui bahwa hasil belajar siswa yang dibelajarkan dengan model Learning Cycle dipadu Think Pair Share secara signifikan berbeda jika dibandingkan dengan hasil belajar siswa yang dibelajarkan dengan model Learning Cycle dipadu Student Team Achievement Divission. Hasil ini didukung oleh data skor rata-rata kelas LC 5E TPS yakni sebesar 79,20 yang lebih tinggi daripada skor rata-rata kelas LC 5E - STAD yakni sebesar 72,05 .

Pada kelas LC 5E - TPS, ketika pembelajaran berlangsung, siswa baik secara individu maupun berpasangan bekerja secara lebih maksimal. Pada tahap think (berpikir individual), siswa membentuk pertanyaan yang diajukan secara individu, sehingga semua siswa di dalam kelas aktif. Selanjutnya pada tahap pair(berpasangan), siswa berpasangan dengan temannya untuk bertukar soal dan mendiskusikan jawaban sebelumnya yang diperoleh secara individu. Melalui diskusi berpasangan, siswa juga dapat lebih maksimal dalam berpartisipasi dalam kelompoknya. Hal tersebut sesuai dengan pendapat Lie (2005) yang menyatakan bahwa model pembelajaran kooperatif tipe TPS memiliki kelebihan antara lain dapat meningkatkan partisipasi siswa, interaksi antar siswa lebih mudah dan kesempatan siswa untuk berkontribusi lebih banyak [12].

Pada kelompok yang diberikan perlakuan dengan model Learning Cycle dipadu Student Team Achievement Divission, pembelajaran berlangsung dengan siswa berkelompok secara heterogen yang masing-masing kelompok terdiri atas 4 siswa. Ketika siswa belajar dalam kelompok heterogen, terdapat keuntungan yaitu siswa dapat saling membantu antar anggota yang mengalami kesulitan. Namun, ketika pembelajaran berlangsung masih terdapat sebagian siswa yang tidak mau berpartisipasi dalam kelompok. Berkaitan dengan hal tersebut, Lie (2005) menyatakan bahwa dalam kelompok berempat atau berlima terdapat kelemahan yaitu kurangnya kontribusi individu dan siswa mudah melepaskan diri dari keterlibatan dan tidak memperhatikan [12]. Hal itu dibuktikan pada 
proses pembelajaran. Ketika siswa belajar dan berdiskusi dalam kelompoknya, dari empat orang anggota kelompok sering kali hanya dua orang saja yang aktif, sedangkan kedua siswa yang lainnya kurang aktif dan terkadang mengobrol sendiri. Hal itu mengakibatkan dua orang anggota yang lain kurang mendapatkan manfaat dari adanya belajar di dalam kelompok tersebut.

Pada kelompok LC 5E - TPS, selama pembelajaran berlangsung, keaktivan tiap siswa lebih maksimal jika dibandingkan dengan kelompok LC 5E - STAD. Diskusi dalam kelompok kecil lebih efektif daripada diskusi dalam kelompok yang lebih besar. Dalam pembelajaran dengan model kooperatif TPS, siswa berpartisipasi secara lebih maksimal dan melaksanakan tugas dengan sungguh-sungguh. Hal tersebut senada dengan pendapat Suprijono (2010) yang menyatakan bahwa melalui tahap (think) berpikir individual dan share dengan pasangan belajar dapat menghindari adanya siswa yang mengobrol dikarenakan setiap siswa memiliki tugas masing-masing [2].

\section{SIMPULAN DAN SARAN}

Berdasarkan hasil penelitian dan pembahasan yang telah diuraikan, dapat dikemukakan beberapa kesimpulan berikut:

1. Kualitas proses belajar baik pada model pembelajaran Learning Cycle dipadu Think Pair Share maupun pada model pembelajaran Learning Cycle dipadu Student Team Achievement Divission adalah baik.

2. Terdapat perbedaan hasil belajar antara siswa yang dibelajarkan dengan model Learning Cycle dipadu Think Pair Share dan siswa yang dibelajarkan dengan model Learning Cycle dipadu Student Team Achievement Divission. Hasil belajar kognitif siswa kelas LC5E-TPS yang lebih tinggi daripada hasil belajar kognitif siswa kelas LC 5E-STAD.Model kooperatif TPS merupakan pilihan yang lebih cocok diintegrasikan pada model pembelajaran Learning Cycle daripada model kooperatif STAD. Adanya pasangan siswa yang hanya terdiri dari dua orang menyebabkan partisipasi siswa dalam proses kelompok lebih maksimal jika dibandingkan dengan partisipasi siswa dalam kelompok yang lebih besar.

\section{DAFTAR PUSTAKA}

[1] Ninis, dkk. 2014. Pembelajaran Kimia dengan Model Learning Cycle 5E untuk Meningkatkan Penguasaan Konsep dan Keterampilan Berpikir Kritis Siswa SMK pada
Pokok Bahasan Termokimia. Surabaya: Prosiding Seminar Nasional Kimia, ISBN : 978-602-0951-00-3Jurusan Kimia FMIPA Universitas Negeri Surabaya.

[2] Slavin, R.E. 2008. Cooperatif Learning Teori Riset dan Praktik. Bandung: Nusa Media.

[3] Suprijono, A. 2010. Cooperative Learning Teori dan Aplikasi PAIKEM. Yogyakarta: Pustaka Pelajar.

[4] Kagan, S.\& Kagan, M. 2009. Kagan Cooperative Learning. Kagan Publishing.

[5] Rahayu, S. 2002. Kecenderungan Pembelajaran Kimia di Awal abad 21. Jurnal MIPA dan Pembelajarannya 31 (2): 271-291

[6] Rahayu, S. 2012. Modul Pengembangan Model Pembelajaran. Malang: Universitas Negeri Malang Panitia Sertifikasi Guru Rayon 115.

[7] Titisari, Ratna. 2010. Upaya Peningkatan Keaktifan dan Prestasi Belajar Siswa dengan Menggunakan Metode STAD pada Pokok Bahasan Pemisahan campuran kelas VII D SMP Negeri 2 Kemalang. Surakarta: FKIP, Skripsi Universitas Negeri Sebelas Maret.

[8] Anah, Dami dkk. 2013. Perbedaan Pengaruh antara Model Kooperatif tipe TPS dan STAD terhadap Hasil Belajar IPS. Surakarta. PGSD FKIP Universitas Sebelas Maret.

[9] Sujianto, A.E. 2009. Aplikasi Statistik dengan SPSS 16.0. Jakarta : PT. Prestasi Pustaka.

[10] Wijaya, T. 2012. Praktis dan Simpel Cepat Menguasai SPSS 20 untuk Olah dan Interpretasi Data. Yogyakarta: Cahaya Atma Pustaka

[11] Arikunto, S. 2008. Dasar-dasar Evaluasi Pendidikan. Jakarta: Bumi Aksara.

[12] Lie, Anita. 2010. Cooperative Learning:Mempraktikkan Cooperative Learning di Ruang-Ruang Kelas. Jakarta: Grasindo.

[13] Trent, K.S. 2013. The Effects of The Instruction Technique Think-Pair-Share On Students Performance in Chemistry. B.S., Nicholls State University. 